\title{
Inhibition of $\beta-1,3-$ Glucan Synthase and Cell Growth of Cryptococcus species by Recombinant Single-chain Anti-idiotypic Antibodies
}

\author{
Dakshnamurthy Selvakumar, Masahiko Miyamoto, Yasuhiro Furuichi, \\ Tadazumi Komiyama
}

Received: October 15, 2005 / Accepted: January 13, 2006

(C) Japan Antibiotics Research Association

\begin{abstract}
Recombinant single-chain fragment variable $(\mathrm{scFv})$ anti-idiotypic antibodies were produced to represent the internal image of a HM-1 killer toxin, which is characterized by a wide spectrum of anti-fungal activity through inhibiting $\beta$-1,3-glucan synthase (GS). We examined if scFv antibodies are active against Cryptococcus species, a human pathogen of increasing medical importance. The anti-cryptococcal activity of $\mathrm{scFv}$ antibodies and HM-1 were assessed by MIC analysis for C. neoformans IFM 40215 and C. albidus NBRC 0612 cells. The $\mathrm{scFv}$ antibodies had strong anti-cryptococcal activity in vitro with $\mathrm{IC}_{50}$ at $1.07 \times 10^{-7}$ to $2.60 \times 10^{-7} \mathrm{M}$ for C. neoformans and C. albidus. Furthermore, the $\mathrm{scFv}$ antibodies potentially inhibited GS of $C$. neoformans with $\mathrm{IC}_{50}$ at $1.27 \times 10^{-7}$ to $2.27 \times 10^{-7} \mathrm{M}$. Both the anti-fungal and anti-GS activities of the $\mathrm{scFv}$ antibodies were markedly neutralized by the monoclonal antibody that neutralizes HM-1 killer toxin.
\end{abstract}

Keywords HM-1 killer toxin, recombinant antiidiotypic antibodies, $\mathrm{scFv}$ antibodies, fungicidal protein, $\beta$-glucan synthase inhibitors, Cryptococcus neoformans, Cryptococcus albidus

T. Komiyama (Corresponding author), D. Selvakumar, M. Miyamoto: Department of Biochemistry, Faculty of Pharmaceutical Sciences, Niigata University of Pharmacy and Applied Life Sciences, 5-13-2 Kamishinei-cho, Niigata 950-2081, Japan, E-mail: tkomiyam@niigata-pharm.ac.jp

Y. Furuichi: GeneCare Research Institute Co. Ltd., 200 Kajiwara, Kamakura 247-0063, Japan.

\section{Introduction}

Opportunistic infections are becoming increasingly common because of the growing number of individuals immunocompromised by chemotherapy or immunosuppressants [1]. Recently, fungal infections have especially become a problem [2,4]. Cryptococcus neoformans causes a serious infection in immuonocompromised individuals, such as AIDS or transplant patients [5]. This fungus is not eradicated with conventional therapeutic approaches, and survivors need lifelong suppressive therapy [6]. The immunosuppressive effects of some cryptococcal capsular compounds, such as glucuronoxylomannan, released during infection, could be an additional deleterious, lifethreatening factor [7].

The gene encoding $\beta$-1,3-glucan synthase (EC 2.4.1.34) has been cloned from $C$. neoformans and has proved essential for viability and growth of fungal cells [8]. $\beta-1,3-$ Glucan synthase (GS), an enzyme localized in the plasma membrane, catalyzes the synthesis of $\beta$-1,3-glucan, a major polymer component of the cell wall of Candida albicans and other fungi [9]. The cell wall serves as a protective barrier for the fungal cell and is essential for fungal viability and shape. Fungal cell wall synthesis enzymes are proven to be effective targets for anti-fungal drugs, in particular, GS is essential for fungal growth and has no mammalian equivalent [10]. A GS inhibitor caspofungin acetate, as a semisynthetic analogue of pneumocandin $B_{0}$, was developed as a broad-spectrum parenteral agent for the treatment of aspergillosis and candidiasis [11]. In general, the most common treatment for fungal infections is based on the use of amphotericin B, 5-flucytosine and 
fluconazole. However, these drugs have repeatedly failed against infections caused by Cryptococcus species [12]. Therefore, the development of novel molecules and alternative therapeutic strategies for the battle against fungal infections is becoming a topical and widely recognized need.

HM-1 killer toxin (HM-1) is produced by Williopsis saturnus var. mrakii IFO 0895 and is characterized by a wide spectrum of anti-fungal activity through inhibiting GS [13 17]. Recently, we developed single chain fragment variable $(\mathrm{scFv})$ anti-idiotypic antibodies with anti-fungal activity by using recombinant DNA technology with the monoclonal antibody that neutralizes the killing activity of HM-1 killer toxin (nmAb-KT). These scFv antibodies have the internal image of HM-1, are characterized by candidacidal activity (Selvakumar et al., unpublished), and kill the various pathogenic strains of Candida albicans and Saccharomyces cerevisiae, through inhibiting GS activity. To our knowledge, no anti-fungal antibody that inhibits GS activity has been previously reported. In this study, we discovered that selected $\mathrm{scFv}$ anti-idiotypic antibodies kill Cryptococcus neoformans through inhibiting GS activity in vitro dose dependently. We believe this is the first study to show recombinant anti-cryptococcal antibodies that potentially inhibit GS activity.

\section{Materials and Methods}

\section{Preparation of scFv Anti-idiotypic Antibodies}

HM-1-like scFv anti-idiotypic antibodies used in this study were produced according to a procedure using the Recombinant Phage Antibody System (Amersham Biosciences) (Selvakumar et al., unpublished). Briefly, female BALB/c mice were immunized subcutaneously and intraperitoneally (booster injection) with $50 \mu \mathrm{g}$ of nmAbKT. Three days after final booster injection the mice were killed, their spleens were removed and the mRNA was isolated from the splenic lymphocytes. The purified mRNA was primed with random hexamers and reverse transcribed. The genes encoding the antibody-variable region of heavy and light chains were amplified, then assembled as scFv genes using a linker fragment, and finally cloned into a specific phagemid vector pCANTAB 5E. Recombinant phages produced in Escherichia coli TG1 were repeatedly panned against nmAb-KT and were screened by using conventional enzyme-linked immunosorbent assay with $\mathrm{nmAb}-\mathrm{KT}$. The selected recombinant phages were infected a non-suppressor E. coli HB2151 to produce soluble recombinant $\mathrm{scFv}$ anti-idiotypic antibodies that were purified by using affinity chromatography. Finally, based on amino acid sequence, four $\mathrm{scFv}$ anti-idiotypic antibodies were selected (designated as scFv-A1, -A2, -A3 and -A4) and used throughout this study.

\section{Measurement of Minimum Inhibitory Concentration (MIC)}

MICs were determined by the standardized protocol for yeasts developed by the National Committee for Clinical Laboratory Standards [18]. Briefly, C. neoformans IFM 40215 and C. albidus strains NBRC 0612 fungal cells were suspended in sterile normal saline and diluted to a concentration of $5 \times 10^{5}$ cells $/ \mathrm{ml}$. The suspension were diluted $1: 1000$ in RPMI 1640 medium with L-glutamine, without bicarbonate, which had been buffered to $\mathrm{pH} 7.0$ with $20 \mathrm{mM}$ HEPES (Sigma, St. Louis, MO). Tubes containing $0.1 \mathrm{ml}$ aliquots of $\mathrm{scFv}$ antibodies or HM-1 at 10 times the final drug concentration were inoculated with $0.9 \mathrm{ml}$ of the diluted suspensions. The tubes were incubated at $30^{\circ} \mathrm{C}$ for 72 hours with shaking. The MIC endpoints were read visually as the lowest concentration at which there was an absence of growth.

\section{In Vitro Anti-fungal Assay}

The qualitative antifungal assay against the fungal isolates was done by using a conventional colony forming unit (CFU) assay, as described previously [19]. Briefly, approximately $5 \times 10^{2}$ cells of $C$. neoformans IFM 40215 or C. albidus NBRC 0612 were suspended in $10 \mu \mathrm{l}$ of phosphate buffered saline (PBS) and were incubated with $100 \mu \mathrm{lsFv}$ antibodies or HM-1 at various concentrations for 16 hours at $37^{\circ} \mathrm{C}$. PBS was used as a control; as a further control, similar fungal cells were prepared by the adding scFv antibodies that were preincubated overnight at $4^{\circ} \mathrm{C}$ with $20 \mu 1$ of nmAb-KT. The fungal cells were incubated with the ScFv antibodies or HM-1, spread on the surface of Sabouraud dextrose agar plates and subsequently incubated at $30^{\circ} \mathrm{C}$. The cells were incubated for 48 hours and their fungal CFU was enumerated. The concentration of $50 \%$ inhibition $\left(\mathrm{IC}_{50}\right)$ was measured by using semilogarithmic graphs. Each experiment was performed in triplicate.

\section{Preparation of Membrane Fraction Containing GS Activity}

The membrane fraction was prepared by using the method described previously [20] with some modifications. $C$. neoformans IFM 40215 cells in mid-exponential phase were collected by centrifugation and washed with $1 \mathrm{mM}$ EDTA. The collected cells were suspended in breaking buffer (consisting of $50 \mathrm{mM}$ Tris- $\mathrm{HCl}(\mathrm{pH} 7.5), 0.5 \mathrm{M}$ $\mathrm{NaCl}, 1 \mathrm{mM}$ EDTA and $1 \mathrm{mM}$ phenylmethanesulfonyl 
fluoride), disrupted by vortexing with glass beads, and then collected by centrifugation ( 5 minutes at $1,000 \times g$ at $4^{\circ} \mathrm{C}$ ). The supernatant was centrifuged for 30 minutes at $100,000 \times g$ at $4^{\circ} \mathrm{C}$. The resulting membrane fraction was homogenized in membrane buffer $(50 \mathrm{mM}$ Tris- $\mathrm{HCl}$ (pH7.5), $10 \mathrm{mM}$ EDTA, $1 \mathrm{mM} \beta$-mercaptoethanol, 33\% glycerol) and stored at $-80^{\circ} \mathrm{C}$.

\section{Measurement of GS Activity}

The assay of GS activity was performed using the method of Cabib and Kang [20]. The reaction mixture consisted of $5 \mathrm{mM}$ UDP-D- $\left[U_{-}{ }^{14} \mathrm{C}\right]$ glucose, $75 \mathrm{mM}$ Tris-chloride (pH 7.5), $0.75 \%$ bovine serum albumin, $25 \mathrm{mM} \mathrm{KF}, 0.75 \mathrm{mM}$ EDTA, $20 \mu \mathrm{M}$ guanosine $5^{\prime}$-[ $\gamma$-thio $]$ triphosphate and $20 \mu \mathrm{l}$ membrane fraction, in a total volume of $40 \mu \mathrm{l}$. The reaction was started by adding the membrane fraction, and the mixture was incubated at $30^{\circ} \mathrm{C}$ for 60 minutes. To measure the inhibitory effect of $\mathrm{scFv}$ antibodies and HM-1 on GS activity, various concentrations of $\mathrm{scFv}$ antibodies or HM-1 were added to the reaction mixture. To examine the neutralization effect of nmAb-KT on GS activity, $10 \mu \mathrm{g} / \mathrm{ml}$ of scFv antibody or $20 \mu \mathrm{g} / \mathrm{ml}$ of HM-1 was incubated with $10 \mu \mathrm{g} / \mathrm{ml}$ of nmAb-KT. The reaction was stopped by adding $250 \mu \mathrm{l}$ of $10 \%(\mathrm{w} / \mathrm{v})$ TCA. After a 10 minutes quenching period, the mixture was filtered through glass microfibre filters (Whatman GF/B). The filters were washed four times with $250 \mu \mathrm{l}$ of $10 \%(\mathrm{w} / \mathrm{v})$ TCA and were further washed twice with $250 \mu 1$ of $95 \%$ ethyl alcohol. The radioactivity retained on the filters was counted using a liquid scintillation counter. The $\mathrm{IC}_{50}$ values were measured by using semi-logarithmic graphs. Each experiment was performed in triplicate.

Table 1 MICs for in vitro susceptibilities of $C$. neoformans IFM 40215 and C. albidus NBRC 0612 to scFv anti-idiotypic antibodies and $\mathrm{HM}-1$

\begin{tabular}{ccc}
\hline \multirow{2}{*}{ Anti-fungal agents } & \multicolumn{2}{c}{ MIC $(\mu \mathrm{g} / \mathrm{ml})$} \\
\cline { 2 - 3 } & C. neoformans & C. albidus \\
\hline scFv-A1 & 12.5 & 25.0 \\
scFv-A2 & 6.25 & 12.5 \\
scFv-A3 & 6.25 & 25.0 \\
scFv-A4 & 12.5 & 12.5 \\
HM-1 & 75.0 & 100 \\
\hline
\end{tabular}

MICs measurements of cell growth of $C$. neoformans and $C$. albidus are described in Materials and Methods.

\section{Results}

\section{MICs for In Vitro Susceptibilities of Cryptococcus} Species to scFv Anti-idiotypic Antibodies and HM-1

MICs for in vitro susceptibilities of $C$. neoformans IFM 40215 and C. albidus NBRC 0612 against scFv antiidiotypic antibodies and HM-1 were summarized in Table 1. Among the scFv antibodies, scFv-A2 and -A3 at MIC $6.25 \mu \mathrm{g} / \mathrm{ml}$ were more potent than $\mathrm{scFv}-\mathrm{A} 1$ and $-\mathrm{A} 4$ against C. neoformans and scFv-A2 and -A4 at MIC $12.5 \mu \mathrm{g} / \mathrm{ml}$ were also more active than $\mathrm{scFv}-\mathrm{A} 1$ and $-\mathrm{A} 3$ against C. albidus. Overall, scFv-A2 was the most active agent for both $C$. neoformans and C. albidus. HM-1 showed MICs at 75 and $100 \mu \mathrm{g} / \mathrm{ml}$ for C. neoformans and C. albidus, respectively.

\section{Anti-fungal Activity of scFv Anti-idiotypic Antibodies and HM-1 against Cryptococcus Species In Vitro}

Figs. $1 \mathrm{~A}$ and $\mathrm{B}$ show the anti-fungal activity of scFv-A2 anti-idiotypic antibody against the pathogenic strain of C. neoformans IFM 40215 by adding PBS as a control. At a concentration $4 \mu \mathrm{g} / \mathrm{ml} \mathrm{scFv}-\mathrm{A} 2$, the growth of $C$. neoformans was strongly inhibited. However the activity of $10 \mu \mathrm{g} / \mathrm{ml} \mathrm{HM}-1$, which was isolated as the original

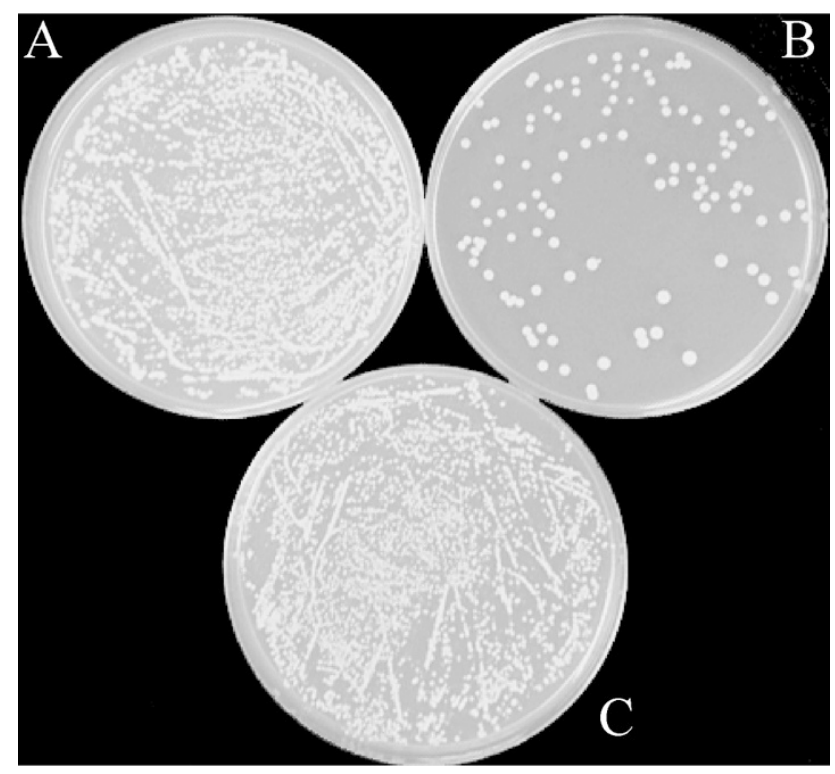

Fig. 1 Anti-cryptococcal activity of scFv-A2 anti-idiotypic antibody.

Effect of scFv-A2 anti-idiotypic antibody on the growth of $C$. neoformans IFM 40215 cells in a CFU assay. A, standardized fungal inocula treated with PBS; B, fungal cells treated with $4 \mu \mathrm{g} / \mathrm{ml}$ of scFv-A2; C, fungal cells treated with scFv-A2 neutralized with $n m A b-K T$. One of the three plates used for each sample is shown. 


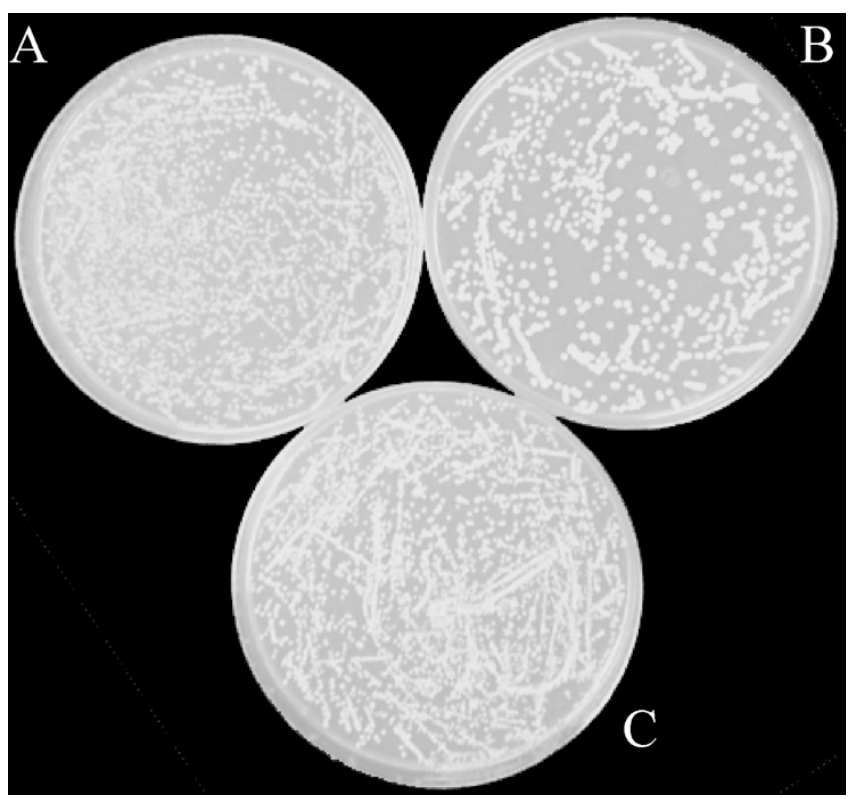

Fig. 2 Anti-cryptococcal activity of HM-1.

Effect of HM-1 on the growth of C. neoformans IFM 40215 cells in a CFU assay. $A$, standardized fungal inocula treated with PBS; $\mathrm{B}$, fungal cells treated with $10 \mu \mathrm{g} / \mathrm{ml} \mathrm{HM}-1$; C, fungal cells treated with HM-1 neutralized with nmAb-KT. One of the three plates used for each sample is shown.

anti-fungal protein, was significantly less than the activity of the same concentration of scFv-A2 (Figs. 2A, B). To measure the potency of $\mathrm{scFv}$ anti-idiotypic antibodies and HM-1 against C. neoformans and C. albidus NBRC 0612, CFU were determined after incubation with increasing concentrations of $\mathrm{scFv}$ antibodies or $\mathrm{HM}-1$. The $\mathrm{IC}_{50}$ values of scFv antibodies were 3.2 to $5.4 \mu \mathrm{g} / \mathrm{ml}\left(1.07 \times 10^{-7}\right.$ to $1.80 \times 10^{-7} \mathrm{M}$ ) against $C$. neoformans, and 6.4 to $7.8 \mu \mathrm{g} / \mathrm{ml}$ $\left(2.13 \times 10^{-7}\right.$ to $\left.2.60 \times 10^{-7} \mathrm{M}\right)$ against $C$. albidus; both results showed strong anti-cryptococcal activity (Table 2). The $\mathrm{IC}_{50}$ of $\mathrm{HM}-1$ was $15.2 \mu \mathrm{g} / \mathrm{ml}\left(1.60 \times 10^{-6} \mathrm{M}\right)$ against C. neoformans, and $15.8 \mu \mathrm{g} / \mathrm{ml}\left(1.66 \times 10^{-6} \mathrm{M}\right)$ against $C$. albidus (Table 2). The lower concentration of scFv antibodies and HM-1 showed no marked effect. The anticryptococcal activities of $\mathrm{scFv}$ antibodies and HM-1 were markedly neutralized by nmAb-KT (Figs. 1C, 2C).

\section{Inhibitory Activity of scFv Anti-idiotypic Antibodies and HM-1 against GS from $C$. neoformans}

To determine if scFv anti-idiotypic antibodies and HM-1 inhibit GS activity of $C$. neoformans IFM 40215, freshly prepared membrane fractions were incubated with different concentrations of scFv antibodies or HM-1. UDP-D-[ $U$ ${ }^{14} \mathrm{C}$ ] glucose was used as the GS substrate. The $\mathrm{scFv}$ antibodies and HM-1 inhibited GS in a concentration-
Table $2 \quad \mathrm{IC}_{50}$ values of scFv anti-idiotypic antibodies and HM-1 against $C$. neoformans IFM 40215 and $C$. albidus NBRC 0612 cell growth

\begin{tabular}{ccc}
\hline \multirow{2}{*}{ Anti-fungal agents } & \multicolumn{2}{c}{$\mathrm{IC}_{50}$ of cell growth } \\
\cline { 2 - 3 } & $\mathrm{M}$ & $\mathrm{M}$ \\
& C. neoformans & C. albidus \\
ScFv-A1 & $1.80 \times 10^{-7}$ & $2.47 \times 10^{-7}$ \\
scFv-A2 & $1.07 \times 10^{-7}$ & $2.13 \times 10^{-7}$ \\
ScFv-A3 & $1.27 \times 10^{-7}$ & $2.60 \times 10^{-7}$ \\
ScFv-A4 & $1.67 \times 10^{-7}$ & $2.20 \times 10^{-7}$ \\
HM-1 & $1.60 \times 10^{-6}$ & $1.66 \times 10^{-6}$ \\
\hline
\end{tabular}

IC $\mathrm{C}_{50}$ measurements of cell growth of $C$. neoformans and $C$. albidus are described in Materials and Methods.

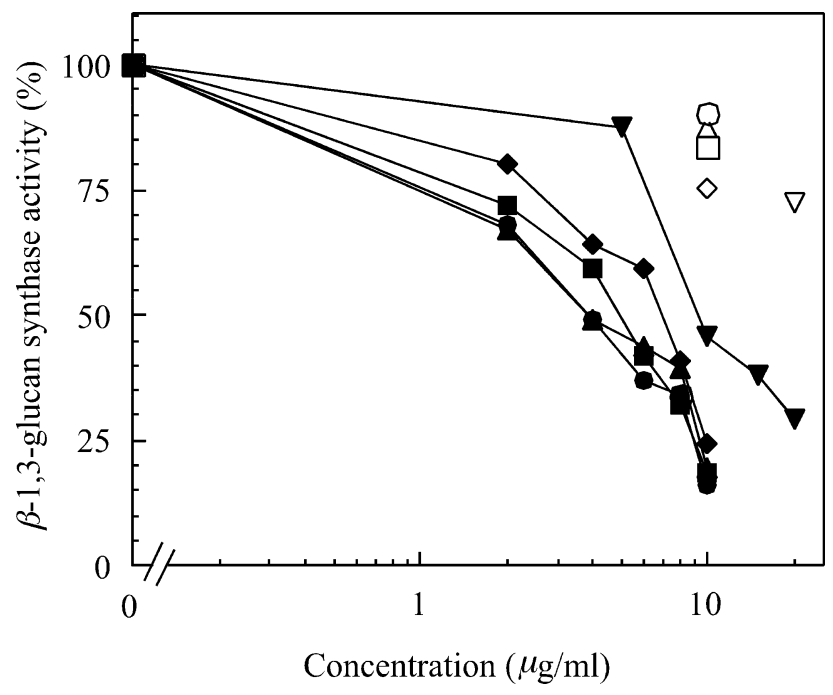

Fig. 3 Inhibition of GS by scFv anti-idiotypic antibodies and $\mathrm{HM}-1$.

The membrane fraction prepared from the cells of $C$. neoformans IFM 40215 and the method of activity measurement were described in Materials and Methods. The activity was expressed by using the sample without ScFv antibodies and HM-1 as $100 \%$. Anti-idiotypic antibodies (scFv) or $\mathrm{HM}-1$ was added to the reaction mixture. $\mathbf{\square}, \mathrm{scFv}-\mathrm{A} 1$; $\bullet$, scFv-A2; $\bullet$ scFv-A3; $\mathbf{\Delta}$, scFv-A4 and $\boldsymbol{\nabla}, \mathrm{HM}-1$. The scFv anti-idiotypic antibodies and HM-1 that were neutralized by nmAb-KT are represented by open symbols: $\square$, scFv-A1; O, scFv-A2; $\diamond$, scFv-A3; $\triangle$, scFv-A4; and $\nabla, \mathrm{HM}-1$.

dependent manner (Fig. 3). The inhibition was expressed as a percentage decreases in GS activity. The $\mathrm{IC}_{50}$ values were 3.8 to $6.8 \mu \mathrm{g} / \mathrm{ml}\left(1.27 \times 10^{-7}\right.$ to $\left.2.27 \times 10^{-7} \mathrm{M}\right)$ for $\mathrm{scFv}$ antibodies and $11.2 \mu \mathrm{g} / \mathrm{ml}\left(1.18 \times 10^{-6} \mathrm{M}\right)$ for HM-1 (Table 3). Inhibition of GS by both $\mathrm{scFv}$ antibodies and HM-1 was markedly neutralized by nmAb-KT at specified 
Table $3 \quad I_{50}$ values of ScFv anti-idiotypic antibodies and HM-1 against GS activity of $C$. neoformans IFM 40215

\begin{tabular}{cc}
\hline scFv antibodies and HM-1 & $\mathrm{IC}_{50}$ \\
\hline & $\mathrm{M}$ \\
ScFv-A1 & $1.67 \times 10^{-7}$ \\
ScFv-A2 & $1.27 \times 10^{-7}$ \\
ScFv-A3 & $2.27 \times 10^{-7}$ \\
ScFv-A4 & $1.27 \times 10^{-7}$ \\
HM-1 & $1.18 \times 10^{-6}$ \\
\hline
\end{tabular}

$I_{50}$ measurements of GS activity of $C$. neoformans membrane fractions are described in Materials and Methods.

concentrations (Fig. 3, open symbols). Because both the anti-fungal and anti-GS $\mathrm{IC}_{50} \mathrm{~s}$ of $\mathrm{scFv}$ antibodies and HM-1 were on the same order of magnitude, there is an implication that these anti-fungal agents may act through inhibition of cell membrane GS.

\section{Discussion}

C. neoformans is an important fungal pathogen that produces firmly established infections in immunocompromised patients. After inhalation of spores into the lung, infection spreads by the bloodstream to the brain where it causes lifethreatening infection of the central nervous system [21]. Cryptococcosis is the fourth most common cause of mortality in patients with AIDS [22, 23]. Currently, 4\% of AIDS patients in the United Kingdom [24], 5 10\% of AIDS patients in the United States [25], and an increasing percentage in the developing countries have cryptococcosis [26]. Even after successful treatment of acute infection with currently available anti-fungal drugs (e.g., amphotericin B, 5 -flucytosine or fluconazole), the recurrence rate is high, and patients require life-long suppressive therapy [27]. The therapeutic options are still unsatisfactory because of the toxicity of available drugs, the inability of these drugs to eradicate the fungus, and the emergence of drug resistance [28]. Therefore, novel and more effective molecules against C. neoformans are needed in the clinic.

In related work, we found that $\mathrm{scFv}$ anti-idiotypic antibodies derived from HM-1 killer toxin have strong candidacidal activity in vitro through inhibiting GS activity (data not shown). However, analysis of the cryptococcal cell walls from in vitro cultures showed that both $\beta-1,3-$ glucan and $\beta$-1,6-glucopyrans are in fungal cells [29]. Nonetheless, production of cryptococcal spheroplasts requires $\beta$-1,3-glucan, which suggest that these linkages are required for cell wall integrity [30]. Therefore, as glucans are critical structural components for $C$. neofromans, we felt encouraged to assess if $\mathrm{scFv}$ anti-idiotypic antibodies derived from HM-1 affect cryptococcal cells. In this study, we showed that $\mathrm{scFv}$ anti-idiotypic antibodies have strong, dose-dependent anti-cryptococcal activity in vitro through inhibiting GS activity, which is particularly relevant because glucan is a major structural component of the cell wall. The gene encoding GS is essential for yeast viability and growth [8], and thus the fact is conceivable that $\mathrm{scFv}$ anti-idiotypic antibodies interfere with regular cell wall formation of C. neoformans.

Molecules able to selectively interact with fungal cell wall components, which are not present in mammalian cells, should be logically considered as putative anti-fungal drugs [31]. The scFv anti-idiotypic antibodies derived from HM-1 killed Cryptococcus cells through inhibiting GS activity. Cryptococcus is unique among fungal pathogens for its major virulence factor, a complex polysaccharide capsule. The scFv-A2 and -A3 MIC at $6.25 \mu \mathrm{g} / \mathrm{ml}$ was active followed by scFv-A1, -A4 and HM-1 against $C$. neoformans. The scFv-A2 and -A4 MIC at $12.5 \mu \mathrm{g} / \mathrm{ml}$ was potent followed by scFv-A1, -A3 and HM-1 against $C$. albidus (Table 1). The $\mathrm{scFv}$ antibodies had a strong anticryptococcal activity against $C$. neoformans and C. albidus in vitro with $\mathrm{IC}_{50}$ at $1.07 \times 10^{-7}$ to $2.60 \times 10^{-7} \mathrm{M}$ and were neutralized by adsorption with nmAb-KT. All four scFv antibodies potentially inhibited GS activity of the membrane fraction of $C$. neoformans at $\mathrm{IC}_{50} 1.27 \times 10^{-7}$ to $2.27 \times 10^{-7} \mathrm{M}$. But in case of $\mathrm{HM}-1$, the $\mathrm{IC}_{50}$ of cell growth and GS activity was ten times higher than for $\mathrm{scFv}$ antibodies (Tables 2, 3). The above results suggested that scFv-A2 which was the most potent inhibitor because of its lowest $\mathrm{MIC}$ and $\mathrm{IC}_{50}$ values against both $C$. neoformans and $C$. albidus may be useful in the treatment of cryptococcosis.

All four scFv anti-idiotypic antibodies potently inhibited the growth of $C$. neoformans and C. albidus to the same extent as their inhibition of GS in the membrane fraction of C. neoformans. These results strongly suggest that inhibition processes by $\mathrm{scFv}$ antibodies and $\mathrm{HM}-1$ are similar. Both the killing of fungal cells and the inhibition of GS by $\mathrm{scFv}$ antibodies and HM-1 were markedly neutralized by nmAb-KT (Figs. 1, 2, 3). Therefore, we speculate that $\mathrm{scFv}$ antibodies and HM-1 share common target molecule(s) that are most likely the cell surface GS. This concept supports the idea that $\mathrm{scFv}$ antibodies may be cytocidal against a wide range of cell wall microorganisms that have glucan, including clinically important opportunistic pathogens.

In conclusion, $\mathrm{scFv}$ anti-idiotypic antibodies showed 
strong, marked anti-fungal activity against Cryptococcus species, the data are consistent with the hypothesis that these $\mathrm{scFv}$ antibodies act by inhibiting the fungal GS, which is the specific target of broad-spectrum anti-fungal drugs. This is particularly relevant, because cryptococcosis is still incurable in immunocompromised patients. These results strongly suggesting a reasonable basis for a novel GS inhibitory agent to cure pathogenic fungal disease like cryptococcosis.

Acknowledgements We thank Dr. Koji Yokoyama of Chiba University for providing the $C$. neoformans, a pathogenic strain. This work was supported by a grant from the Ministry of Education, Science, Sports and Culture of Japan.

\section{References}

1. Myskowski PL, White MH, Ahkami R. Fungal disease in the immunocompromised host. Dermatol Clin 15: 295-305 (1997)

2. Van Burik JA, Magee PT. Aspects of fungal pathogenesis in humans. Annu Rev Microbiol 55: 743-772 (2001)

3. Anaissie E. Opportunistic mycoses in the immunocompromised host: experience at a cancer center and review. Clin Infect Dis 14: 43-53 (1992)

4. Latge JP, Calderone R. Host-microbe interactions: fungi invasive human fungal opportunistic infections. Curr Opin Microbiol 5: 355-358 (2002)

5. Casadevall A, Perfect JR. Human Cryptococcosis. In Cryptococcus neoformans. Ed., Casadevall A, Perfect JR. pp. 407-756, ASM Press Washington D.C. (1998)

6. Powderly WG. Recent advances in the management of cryptococcal meningitis in patients with AIDS. Clin Infect Dis 22: 119-123 (1996)

7. Vecchiarelli A. Immunoregulation by capsular components of Cryptococcus neoformans. Med Mycol 38: 407-417 (2000)

8. Thompson JR, Douglas CM, Li W, Jue CK, Pramanik B, Yuan X, Rude TH, Toffaletti DL, Perfect JR, Kurtz M. A glucan synthase FKS1 homolog in Cryptococcus neoformans is single copy and encodes an essential function. J Bacteriol 181: 444-453 (1999)

9. Ruiz-Herrera J. Fungal glucans. In Fungal cell wall: Structure, Synthesis, and Assembly. pp. 59-88, Boca raton, FL, CRC Press (1992)

10. Gordee RS, Debono M. The Fungal cell wall-a target for lipopeptide antifungal agents. New approaches for antifungal drugs. Ed., Frenandes PB. pp. 46-63, Boston, Birk Hauser Press (1992)

11. Onishi J, Meinz M, Thompson J, Curotto J, Dreikorn S, Rosenbach M, Douglas C, Abruzzo G, Flattery A, Kong L, Cabello A, Vicente F, Pelaez F, Diez MT, Martin I, Bills G,
Giacobbe R, Dombrowski A, Schwartz R, Morris S, Harris G, Tsipouras A, Wilson K, Kurtz MB. Discovery of novel antifungal (1,3)- $\beta$-D-glucan synthase inhibitors. Antimicrob Agents Chemother 44: 368-377 (2000)

12. Kordossis T, Avlami A, Velegraki A, Stefanou I, Georgakopoulos G, Papalambrou C, Legakis NJ. First report of Cryptococcus laurentii meningitis and a fatal case of Cryptococcus albidus cryptococcaemia in AIDS patients. Med Mycol 36: 335-339 (1998)

13. Yamamoto T, Hiratani T, Hirata H, Imai M, Yamaguchi $H$. Killer toxin from Hansenula mrakii selectively inhibits cell wall synthesis in sensitive yeast. FEBS Lett 197: 50-54 (1986)

14. Yamamoto T, Imai M, Tachibana K, Mayumi M. Application of monoclonal antibodies to the isolation and characterization of a killer toxin secreted by Hansenula mrakii. FEBS Lett 195: 253-257 (1986)

15. Yamamoto T, Uchida K, Hiratani T, Miyazaki T, Yagiu J, Yamaguchi $\mathrm{H}$. In vitro activity of the killer toxin from yeast Hansenula mrakii against yeasts and molds. J Antibiot 4: 398-403 (1988)

16. Takasuka T, Komiyama T, Furuichi Y, Watanabe T. Cell wall synthesis specific cytocidal effect of Hansenula mrakii toxin-1 on Saccharomyces cerevisiae. Cel Mol Biol Res 41: 575-581 (1995)

17. Komiyama T, Ohta T, Urakami H, Shiratori Y, Takasuka T, Sato M, Watanabe T, Furuichi Y. Pore formation on proliferating yeast Saccharomyces cerevisiae cell buds by HM-1 killer toxin. J Biochem (Tokyo) 119: 731-736 (1996)

18. National Committee for Clinical laboratory Standards. Reference method for broth dilution antifungal suceptibility testing of yeasts. Approved standard M27-A. National Committee for Clinical Laboratory Standards, Wayne, Pa. (1997)

19. Magliani W, Conti S, de Bernardis F, Gerloni M, Bertolotti D, Mozzoni P, Polonelli L. Therapeutic potential of antiidiotypic single chain antibodies with yeast killer toxin activity. Nat Biotechnol 15: 155-158 (1997)

20. Cabib E, Kang MS. Fungal 1,3-beta-glucan synthase. Methods Enzymol. Vol. 138, Ed., Ginsberg V., pp. 637-642, New York, Academic Press (1987)

21. Kauffman CA, Carver PL. Antifungal agents in the 1990s. Current status and future developments. Drugs 53: 539-549 (1997)

22. Chandler FW. Pathology of the mycoses in patients with the acquired immunodeficiency syndrome (AIDS). Curr Top Med Mycol 1: 1-23 (1985)

23. Eng RH, Bishburg E, Smith SM, Kapila R. Cryptococcal infections in patients with acquired immune deficiency syndrome. Am J Med 81: 19-23 (1986)

24. Knight FR, Mackenzie DW, Evans BG, Porter K, Barrett NJ, White GC. Increasing incidence of cryptococcosis in the United Kingdom. J Infect 27: 185-191 (1993)

25. Chuck SL, Sande MA. Infections with Cryptococcus neoformans in the acquired immunodeficiency syndrome. $\mathrm{N}$ 
Engl J Med 21: 794-799 (1989)

26. Perfect JR. Cryptococcosis. Infect Dis Clin North Am 3: 77-102 (1989)

27. Zuger A, Louie E, Holzman RS, Simberkoff MS, Rahal JJ. Cryptococcal disease in patients with the acquired immunodeficiency syndrome. Diagnostic features and outcome of treatment. Ann Intern Med 104: 234-240 (1986)

28. Friese G, Discher T, Fussle R, Schmalreck A, Lohmeyer J. Development of azole resistance during fluconazole maintenance therapy for AIDS-associated cryptococcal disease. AIDS 23: 2344-2345 (2001)

29. James PG, Cherniak R, Jones RG, Stortz CA, Reiss E. Cellwall glucans of Cryptococcus neoformans CAP 67. Carbohydr Res 198: 23-38 (1990)

30. Bastide JM, Hadibi EH, Bastide M. Taxonomic significance of yeast sphaeroplast release after enzymatic treatment of intact cells. J Gen Microbiol 113: 147-153 (1979)

31. Selitrennikoff CP, Nakata M. New cell wall targets for antifungal drugs. Curr Opin Investig Drugs 4: 200-205 (2003) 